This is an open access article under the terms of the CC-BY 3.0 License.

Peer review method: Double-Blind

Date of acceptance: September 16, 2020

Date of publication: November 11, 2020

Original scientific article

DOI: https://www.doi.org/10.47305/JLIA2060045r

\title{
THE GUARDA NACIONAL REPUBLICANA 4S PATH: A STRATEGIC APPROACH FOCUSING ON HUMAN LIFE
}

\author{
Adérito Rodrigues \\ Guarda Nacional Republicana, Portugal \\ ORCID iD: https://orcid.org/0000-0003-4076-4884 \\ rodrigues.ag3@gnr.pt \\ Adriana Martins \\ Guarda Nacional Republicana, Portugal \\ ORCID iD: https://orcid.org/0000-0002-5494-0992 \\ martins.afg1@gnr.pt \\ Annabella Almeida \\ Guarda Nacional Republicana, Portugal \\ ORCID iD: https://orcid.org/0000-0002-4932-4730 \\ almeida.at@gnr.pt
}

\begin{abstract}
The pandemic caused by the SARS-COV-2 virus not only accentuated the responsibility of the Security Forces to protect human life but also challenged the ability to manage change that, in a highly demanding environment, lacks integrated approaches that would enhance the collective and cooperative effort to share a common commitment. The Portuguese Guarda Nacional Republicana has guided its action according to the 45 strategic path, based on security, safety, social and support pillars, and on integrated strategic planning that, achieved by joint, preventive, educational awareness-raising and intervention actions, and by current proximity patrolling, have enabled obtaining social support and protecting military personnel lives and citizens lives. These tools simultaneously improve operational synergies enhanced by close cooperation and collaboration relations with several partners, doing justice to the premise that together we are capable and thus preventing anyone from falling behind.
\end{abstract}




\section{INTRODUCTION}

The pandemic caused by the SARS-COV-2 virus has made the global citizens even more vulnerable to universal and borderless threats, and has put greater emphasis on the accountability of the Security Forces to protect human lives and, above all, to empower it. It has simultaneously required that they act with respect for the dignity and integrity of the human person and based on the principles of the democratic rule of law, according to the premise of utmost containment with minimum disturbance, in view of conducts and behaviours that disregard the value of human life and may contribute to worsen national public health.

In this context, it is vital to tackle the following questions: How can Security Forces safeguard the human lives of their personnel without compromising the lives that they have a responsibility to protect? What kind of approaches can Security Forces adopt to protect human lives in global pandemic situations where it is imperative to maintain public order and tranquillity without affecting individual freedoms and human and fundamental rights? How can Security Forces act without compromising the necessary balance between the preservation of individual rights and the human security of each and every one in global pandemic situations? The purpose of this paper is to analyse the actions of the Guarda Nacional Republicana (GNR) throughout the term of the State of Emergency that was declared in Portugal.

\section{FRAMEWORK: THE STATE OF EMERGENCY IN PORTUGAL}

On 30 January 2020, the World Health Organization declared the epidemic caused by the SARS-COV-2 virus, detected in Wuhan, in the People's Republic of China, as an international public health emergency and classified it as pandemic, on 11 March 2020, due to the wide range of countries affected, of which Portugal is an example.

The State of Emergency was declared in Portugal, from 18 March to 02 May 2020, to prevent the transmission of the cited virus and contain the expansion of the Corona Virus Disease (COVID-19), establishing a set of urgent extraordinary measures and rules that restricted rights, freedoms and guarantees. ${ }^{1}$ Example of which is the partial suspension of the exercise of the following rights: to move throughout national territory; to private property and economic initiative; of workers; of international movement; of assembly and demonstration; of freedom of belief in its collective dimension; to learn and teach; of data protection and resistance.

\footnotetext{
${ }^{1}$ During the State of Emergency all the urgent extraordinary measures and rules that restricted rights, freedoms and guarantees were declared by three Presidential Decrees. The Presidential Decree no. 14A/2020, of 18 March, declared the initial phase of the state of emergency. This Presidential Decree was renewed by the Presidential Decree no. 17-A/2020 which was also renewed by the Presidential Decree no. $20-A / 2020$.
} 
Due to such situation, Security Forces have been assigned the responsibility of supervising legal restrictions, focusing their action on the preventive-educational and repressive dimensions.

In the repressive dimension, it was incumbent on them to close businesses or to cease activities that were forbidden from being carried out or should not be in operation, to report crimes of disobedience due to violation of prophylactic isolation and to direct those who violated such obligation to their homes.

In the educational dimension, it was incumbent on them to carry out counselling and advisory actions to all people who despite not being forbidden from leaving their homes should avoid doing so, by explaining how they should act and, thus, avoid excess outgoings and recommending that they stay at home as a result of the special protection duty or the general duty to stay at home.

\section{THE GNR AND THE 4S STRATEGIC PATH IN THE STATE OF EMERGENCY}

The GNR is a Security Force of a military nature, constituted by military personnel organized in a special body of troops, whose mission is to ensure democratic legality, guarantee internal security and citizens' rights, as well as to collaborate in the implementation of the national defence policy, in accordance with the Constitution and the Article 1 of the GNR Organic Law. The GNR is also the outward face of the democratic rule of law in approximately $94 \%$ of the national territory, including the land border and the territorial sea, constituting itself as a key element in articulating political decisions with the strategic and operational police action close to the citizen. Sometimes it is the only representative among the most vulnerable, unprotected and/or isolated.

One of the GNR's ongoing institutional intentions has been to consolidate itself as a reference of excellence centred on persons (Guarda Nacional Republicana 2015), that is, on the military personnel and the citizens. Throughout the State of Emergency, such fact was possible due to the $4 \mathrm{~S}$ strategic path that has mobilized and concentrated efforts in the security, safety, social and support dimensions. ${ }^{2}$ The security component

(...) represents the most traditional axis in terms of GNR action, highlighting all activities in favour of the called 'Right to Security', assured daily through operations, patrolling, inspection and investigation. These are the activities that most contribute to complying with the law, to preventing and combating criminal activity and to maintaining public order, and are carried out throughout all of the territorial sea and national territory, focused on crime and legality in general, and specifically on road, environment, tax and customs

\footnotetext{
${ }^{2}$ The strategic path was presented by His Excellency the Lieutenant General Luís Francisco Botelho Miguel, the General Commander of the Guarda Nacional Republican during the speech given at his swearing-in on 04 June 2018.
} 
areas, as well as in monitoring the coastline, the seashore and the land borders [whereas the safety component relates to the area of] Protection and Rescue, in an active, robust participation (...) (Botelho Miguel 2018).

On the other hand, the social component is safeguarded:

(...) by means of Special Prevention and Policing Programs, acting socially from the outset on a wide range of initiatives aimed at deepening a close and trust-based relationship with the population, taking special care of the most fragile and vulnerable, such as supporting the elderly, children and young people and, not least, safeguarding their assets, with the aim of strengthening the feeling of security of each and every one (Botelho Miguel 2018).

The support component encompasses "(...) all activities supporting the operational activity, (...)" (Botelho Miguel 2018) and focuses on "(...) cooperation, collaboration and support, with the different actors of the national security system, in the internal dimension, as well as in external relations assumed in national and bilateral commitments (...)" (Botelho Miguel 2018).

The operationalization of the 4S strategic path, during the State of Emergency, was carried out through balanced actions among citizens and local, national and international partners, which sought to identify common problems and shared solutions, in an environment that required resilience, solidarity and good sense in view of the turbidity between what is admissible - at most acceptable - and what is forbidden, avoiding uncertainties, arbitrariness and conflicts of interest.

In the face of the exceptionality of this situation and in the light of the measures decreed by the Portuguese government, the GNR preventively and proactively adopted measures and promoted responses to ensure the balance between the rights to the life and integrity of persons - specifically the military personnel and the citizens - protected by the Portuguese Constitution, and the urgent measures, which legitimatized and framed the restriction of rights, freedoms and guarantees. Thus, the 4S strategic path was distinctly targeted at military personnel and citizens.

\section{THE GNR'S RESPONSIBILITY TO PROTECT THE MILITARY PERSONNEL IN LIGHT OF THE 4S STRATEGIC PATH}

In a perspective directed at its most precious asset and conscious that it could only protect citizens if the military staff was protected, in due time and prior to the State of Emergency, the GNR prevented this imperative by implementing a set of internal contingency measures to prevent and minimize the transmission of the SARS-COV-2 virus and contain the COVID-19. 
Within the framework of the security component and through the Contingency Plan Prevention, Control and Monitoring of infection by COVID-19 and its five additional instructions the following was promoted: communication and information actions to each and every GNR military element through the dissemination of 22information bulletins $^{3}$ that raised their awareness of the individual measures to be adopted to prevent, control and monitor the pandemic and manage emotional stress; careful management of human resources within the frame of reducing the concentration of military personnel in spaces, promoting teleworking and video teleconferencing; the suspension of the permanent execution standard that regulates the weekly reference working hours of the GNR military personnel, enabling an increase in the daily service time up to a maximum of 12 hours and of the number of military staff simultaneously enjoying rest days; and the reorganization of the physical space of the public attendance services.

Within the framework of the safety component, the GNR units and vehicles were decontaminated. In the context of the support component, the permanent follow-up and monitoring of epidemiological cases and prophylactic isolation (24/7) should be highlighted. It was possible for the military elements to report their state of health and symptomatology evolution through an IT application and digital means monitored in the situation room of the GNR Clinical Centre, as well as by carrying out swab tests throughout the continental territory. This measure enabled the conducting of $618 \mathrm{swab}$ tests; following-up clinically 1,785 military personnel and psychologically 913 military personnel. Simultaneously, protective material was acquired, namely visors, masks, gloves and disinfectant for individual use and in contact with persons.

In the context of the social component, the Project 65 Far+Near aimed at retired military personnel was developed and whose results will be subsequently demonstrated.

In a universe of 23,009 military elements, the simultaneous combination of these measures applied during the State of Emergency was reflected in: 26 military personnel infected with COVID-19; 291 military personnel in prophylactic isolation and 426 military personnel were quarantined. No military element passed away.

\section{THE GNR'S RESPONSIBILITY TO PROTECT CITIZEN IN ACCORDANCE WITH THE 4S STRATEGIC PATH}

Within the framework of the security component, the rights to the life and integrity of citizens were safeguarded through several actions aimed at (primarily) sensitizing, informing and raising awareness as to the special protection and retreat obligations, as well as to proactively supervise restrictive legal measures, discouraging the practice of unnecessary and unsafe behaviours.

\footnotetext{
${ }^{3}$ All data presented was monitored by the Guarda Nacional Republicana.
} 
Among these actions the following are highlighted: current daily proximity patrolling ${ }^{4}$ as a key element in maintaining strong in the prevention, awareness and repression of risk behaviours by citizens and the eight operations ${ }^{5}$ which engaged 109,769 military personnel, who carried out 52,220 patrols, sensitised and informed 560,875 citizens and supervised 383,689 citizens.

In inspection actions pertaining to non-compliance, citizens generally respect the legal restrictions as well as GNR orientations, attending to the very satisfactory Results of Compliance shown in Chart 1. In total and during the State of Emergency, 22,751 citizens followed GNR orientations regarding the special protection duty and 82,911 citizens adopted GNR orientations concerning the general duty to stay at home. These results demonstrate the civic and conscious attitude of most citizens who promptly and voluntarily complied with GNR indications, in the case of non-compliance, especially pertaining to protection and retreat obligations.

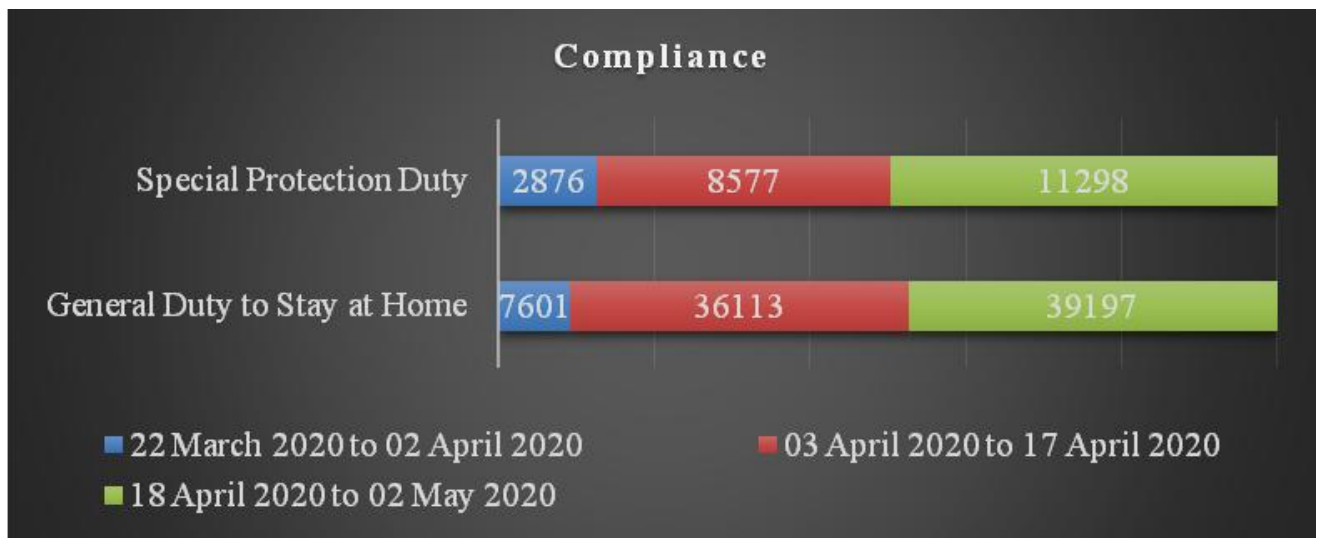

Chart 1: Results of Compliance by Citizens

Within the framework of the safety component, 2,289 actions were carried out to decontaminate vehicles ${ }^{6} ; 69$ actions to decontaminate facilities ${ }^{7} ; 177$ awareness-raising actions by using drones to communicate alerts and sound messages to citizens.

\footnotetext{
${ }^{4}$ This proximity patrolling was carried out through vehicle patrolling, patrolling on foot, trinomials, horse patrols, river patrols and sea patrols.

${ }^{5}$ The following eight Operations were carried out: Operation COVID-19 Containment; Operation COVID-19 Controlled Border; Operation COVID-19 Sanitary Enclosure of Ovar; Operation COVID-19 Stay at Home; Operation COVID-19 General Retreat; Operation COVID-19 Easter at Home; Operation COVID-19 Retrovirus and Operation COVID-19 Safe Transition.

${ }^{6}$ The decontamination of vehicles, namely vehicles belonging to the GNR, the National Institute of Medical Emergency, the Portuguese Red Cross and Fire fighters in the decontamination lines established in Que/uz and Vila Nova de Gaia.
} 
Under the framework of the social component 63,069 awareness-raising actions were carried out (mostly) by military personnel of the criminal prevention and community policing sections among the most vulnerable citizens, with special care for the elderly living alone and/or isolated, and the result culminated in the creation of the Program 65 Far+Near. This program promoted the establishment of a network of contacts and support to the elderly and the retired GNR military personnel, strengthening the intergenerational connection, the institutional cohesion and the mutual support. Within this program, 32,964 elderly persons were sensitised and 191 elderly persons were flagged; 3,797 retired military personnel were sensitised and 26 retired military personnel were flagged.

Also within the framework of this component, the GNR paid particular attention to the solidarity component that enhanced the conscious responsibility to protect the most vulnerable and underprivileged with signs or certainties of COVID-19. The following actions are highlighted: the GNR monitored hundreds of Roma and Hindustani citizens; supported in the accommodation transferring processes of beneficiaries of nursing and retirement homes, and subsequent rehousing; collaboratively accompanied several local health authorities; carried out numerous accompaniments and convoys of medical and critical equipment since their arrival on national territory until their destinations.

In support of the operational commitment and within the framework of the support component, the GNR carried out 430 awareness-raising publications on social networks - Facebook; Instagram; Twitter - which totalled 9,147,685 interactions and 414 responses provided to citizens through the COVID-19 line created specially to inform, clarify and support citizens.Still, within the support component, in a coordinated effort with the mass media ${ }^{8}$, the GNR conducted a total of 752 television broadcasting, 13 studio broadcasting, 151 radio broadcasting, 11 broadcasting via Skype, 257 articles in the national written press and 415 articles in the regional written press.

These actions were aimed at disseminating and clarifying the confinement rules, appealing to civic awareness, autonomy and collective and individual responsibility to voluntarily comply with everyone's obligations and also the legally imposed restrictions, thus discouraging their non-compliance. In addition and with a view to strengthening operational synergies, the GNR established cooperative relations with various partners ${ }^{9}$ that enabled enhancing the collective, collaborative and cooperative effort in the coordination and articulation of joint operational, awareness-raising and information actions.

\footnotetext{
${ }^{7}$ The decontamination of facilities included GNR Units and buildings such as Nursing Homes, Private Institutions of Social Solidarity, Hotels, Spiritual Training Centres, and Basic Units of the National Health Service for providing assistance and primary health care to the population.

${ }^{8}$ Relations have been established with local, regional and national mass media.

${ }^{9}$ Relations have been established with local, regional and national partners.
} 
It should be highlighted that 5 press conferences and several operational actions were carried out, some in coordination and others jointly with the Portuguese Public Security Police; the organization of procedures and actions with the Portuguese Immigration and Borders Service, vital in the pursuit of the Controlled Border Operation and in the sharing of information with the Spanish Guardia Civil necessary in the structuring of operational procedures, in particular in the common land border between Portugal and Spain ${ }^{10}$.

The 4S strategic path was also supported by an integrated strategic planning that enabled aligning the strategic and political guidelines and decisions with the tactical and operational police action/intervention. This integrated strategic planning, fostered by video teleconferencing, linked several areas - such as human, logistical and financial resources, operations, intelligence and criminal investigation, communications and information systems, public and international relations, health, education and training and dimensions - strategic, operational and tactical - based on an ongoing process of analysing, monitoring and assessing daily situations that resulted in the development of tools to aid strategic decision-making. These tools enabled optimising the coordination and control capacity of different levels of operational command, and administrative and organizational management, in a collective and joint effort that was dynamic, flexible, responsible, and duly oriented to achieve a common and shared aim: the human security of each and every one.

\section{CONCLUSION}

During the State of Emergency, the GNR was committed to protecting human lives - that is, of its military personnel and of citizens - mitigating the risks and preserving the integrity and dignity of each and every one, according to the eternal motto 'For the Law and for the People', in a demanding and risky environment which required resilience and solidarity. This commitment was underpinned by the $4 \mathrm{~S}$ strategic path, based on the security, safety, social and support pillars, and the integrated strategic planning that focused the collective, cooperative and collaborative effort on sharing anxieties and concerns and on seeking joint solutions to common problems.

\footnotetext{
${ }^{10}$ In addition to the close relations established with the Public Security Police, the Immigration and Borders Service and the Spanish Guardia Civil, the GNR also established close contacts with the National Emergency and Civil Protection Authority; the municipal and local authorities and entities; the representatives of the Republic for the Autonomous Regions of Madeira and Azores; the regional secretariat for health and civil protection of Madeira; the National Institute of Medical Emergency, the Portuguese Red Cross and Fire-fighters; the National Association of Portuguese Municipalities; the regional government coordinators; the Attorney General's Office; the National Institute of Legal Medicine and Forensic Sciences.
} 
On the one hand, these tools enabled to reconcile the rights to life and individual integrity of each military element with the professional duty, subordinated to the national interest and exclusively serving the public interest and the citizen. Thus, it was possible for those who swore to protect others with their own lives to be fully available to say Present, for each and every one, and to strengthen the institutional awareness of its responsibility to protect.

At the same time, the results obtained throughout the State of Emergency reveal the pursuit of an intense and integrated prevention approach which, among the citizens, has been made operational through several educational awareness-raising and information actions as a means of safeguarding human safety and capacity-building.

Such actions were carried out by current daily proximity patrolling and enhanced by relations with local, national and international partners, by public administration bodies and by information and communication technologies and means highlighting the $9,147,685$ interactions obtained on social networks, the 927 broadcasts made with the mass media and the 672 articles published in the written press. Thus, such approach and these actions enabled being close to citizens making them aware and empowering them for the best practices to be adopted to prevent and hinder the transmission of the SARS-COV-2 virus, while deterring them from non-complying with the exceptional measures established and making the GNR action easier. The eight Operations coupled with the current proximity patrolling promoted ongoing human face-to-face and reliable interactions allowing for maintaining the vigour in preventing and, when absolutely necessary, proportionally, adequately and gradually repressing risk behaviours and consequent compliance. Examples of this are the results attained among citizens who, when made aware and informed, promptly comply with the GNR orientations.

On the other hand, the $4 \mathrm{~S}$ strategic path and the strategic planning promoted support and solidarity links with the most vulnerable and underprivileged, preventing inequalities and discrimination and avoiding anyone from falling behind. Examples of this are the results achieved with the creation of the Project $65 \mathrm{Far}+\mathrm{Near}$, in which 36,761 persons were sensitised and 217 persons were flagged; the monitoring of several Roma and Hindustani communities and the decontamination actions mostly in nursing homes. They simultaneously fostered cooperation and collaboration among the GNR, citizens and several partners, giving due recognition to the fact that together we will succeed in protecting and preserving the fundamental human asset: Life, the lives of the military personnel and the lives of the citizens.

Aware of the conclusions, other issues arise: given that citizens are integral elements in preserving the security and human rights, of each and every one, how can they be involved to better cooperate and collaborate with the Security Forces, in pandemic situations? Can citizens carry out awareness-raising and information actions jointly with the Security Forces? In what way did that make sense? 


\section{REFERENCES}

1. Botelho Miguel, L. F (04 June 2018)The speech given by His Excellency the Lieutenant General Luís Francisco, The General Commander of the Guarda Nacional Republicana at his swearing-in. Lisbon.

2. Guarda Nacional Republicana. (2015). Estratégia da Guarda 2020: Uma Estratégia de Futuro.Accessed July 06, 2020, from https://www.gnr.pt/InstrumentosGestao/estrategia_2020.pdf.

3. Presidential Decree no. 14-A/2020, of 18 March, which declares the state of emergency, on the basis of verifying a situation of public calamity.

4. Presidential Decree no. 17-A/2020, of 02 April, which renews the declaration of state of emergency, on the basis of verifying a situation of public calamity.

5. Presidential Decree no. 20-A/2020, of 17 April, which proceeds the second renewal of the declaration of the state of emergency, on the basis of verifying a situation of public calamity.

6. GNR Organic Law.

7. GNR Contingency Plan- Prevention, Control and Monitoring of infection by COVID-19, implemented on 03 March 2020.

8. Additional instructions no. 01 to the Contingency Plan - Prevention, Control and Monitoring of infection by COVID-19, implemented on 05 March 2020.

9. Additional instructions no.02 to the Contingency Plan - Prevention, Control and Monitoring of infection by COVID-19, implemented on 10 March 2020.

10. Additional instructions no.03 to the Contingency Plan - Prevention, Control and Monitoring of infection by COVID-19, implemented on 13 March 2020.

11. Additional instructions no.04 to the Contingency Plan - Prevention, Control and Monitoring of infection by COVID-19, implemented on 16 March 2020.

12. Additional instructions no.05 to the Contingency Plan - Prevention, Control and Monitoring of infection by COVID-19, implemented on 17 March 2020.

13. GNR Operational Directive on Operation COVID-19 Containment.

14. GNR Operational Directive on Operation COVID-19 Controlled Border.

15. GNR Operational Directive on Operation COVID-19 Sanitary Enclosure of Ovar.

16. GNR Operational Directive on Operation COVID-19 Stay at Home.

17. GNR Operational Directive on Operation COVID-19 General Retreat.

18. GNR Operational Directive on Operation COVID-19 Easter at Home.

19. GNR Operational Directive on Operation COVID-19 Retrovirus.

20. GNR Operational Directive on Operation COVID-19 Safe Transition. 